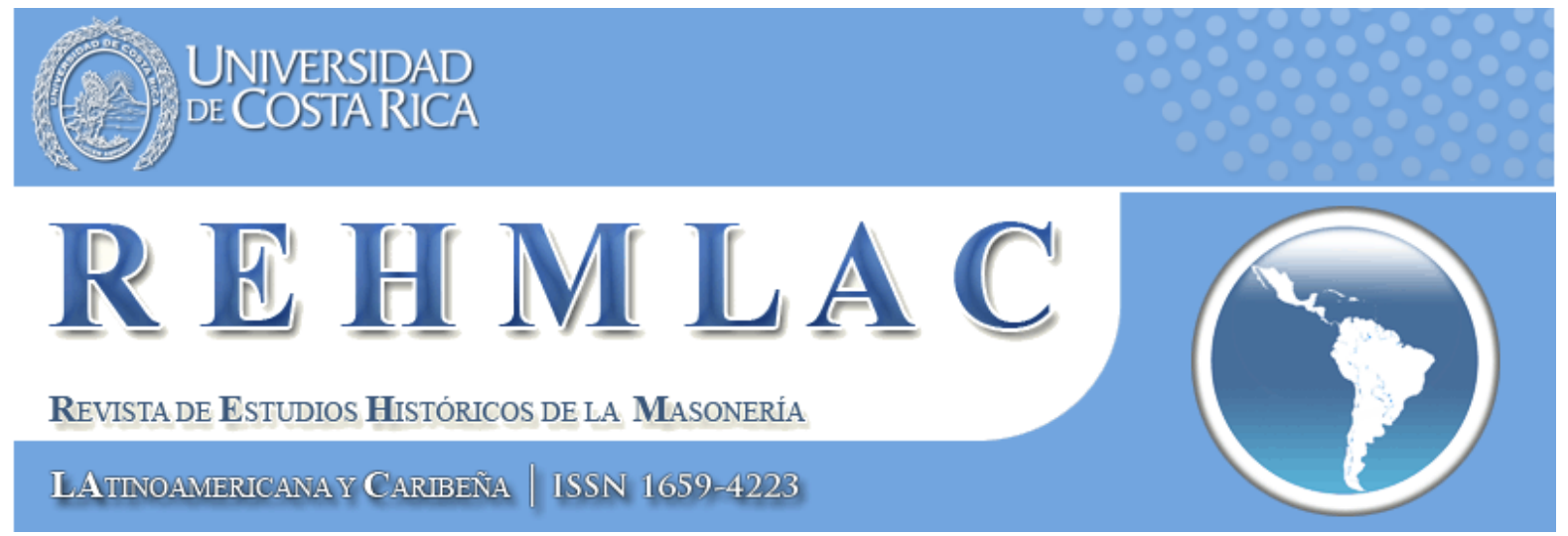

"La historia tiene la palabra. II República española y la masonería 75 años después, en: Cultura Masónica VI, no. 19 (2014), coordinado por Yván Pozuelo Andrés"

José-Leonardo Ruiz Sánchez 
(C) José-Leonardo Ruiz Sánchez y REHMLAC.

\section{Equipo REHMLAC}

Consejo Científico:

Miguel Guzmán-Stein (Universidad de Costa Rica, Costa Rica)

José Antonio Ferrer Benimeli (Universidad de Zaragoza, España)

Margaret Jacob (University of California Los Angeles, United States)

Eduardo Torres Cuevas (Universidad de La Habana, Cuba)

María Eugenia Vázquez Semadeni (Stanford University, United States)

Éric Saunier (Université du Havre, France)

Andreas Önnerfors (Lunds universitet, Sverige)

Samuel Sánchez Gálvez (Universidad Carlos Rafael Rodríguez de Cienfuegos, Cuba)

Roberto Valdés Valle (Universidad Centroamericana “José Simeón Cañas”, El Salvador)

Céline Sala (Université de Perpignan, France)

Dominique Soucy (Université de Franche-Comté, France)

Guillermo de los Reyes Heredia (University of Houston, United States)

Dévrig Mollès (Université de Strasbourg, France)

Felipe Santiago del Solar Guajardo (Universidad ARCIS, Santiago de Chile)

Carlos Francisco Martínez Moreno (Universidad Nacional Autónoma de México, México)

Michel Goulart da Silva (Universidade do Estado de Santa Catarina, Brasil)

Correctores de estilo:

Sylvia Hottinger (Centro de Estudios Históricos de la Masonería Española, España)

Kyle Jackson (University of California Los Angeles, United States)

Diseñador y administrador $W e b$ :

Luis Martín Valverde Alfaro (Universidad de Costa Rica, Costa Rica)

Editor:

Yván Pozuelo Andrés (IES Universidad Laboral de Gijón, España)

Correo electrónico: yvan@edu.xunta.es

Director:

Ricardo Martínez Esquivel (Universidad de Costa Rica, Costa Rica)

Correo electrónico: ricardo.martinezesquivel@ucr.ac.cr

Dirección Web: rehmlac.com/

Correo electrónico: info@rehmlac.com

Apartado postal: 243-2300 San José, Costa Rica 


\section{Citado en:}

Academia.edu

Aladin. WRLC. Libraries Catalog

AFEHC. Asociación para el Fomento de los Estudios Históricos en Centroamerica

Biblioteca de Georgetown

CRICCAL, Université Sorbonne Nouvelle Paris 3

CERGE EI. Portál elektronických časopisů. Univerzita Karlova v Praze

Departamento de Filosofía de la Universidad Centroamericana "José Simeón Cañas"

Dialnet, Universidad de la Rioja

Directorio y recolector de recursos digitales del Ministerio de Cultura de España

DOAJ. Directory of Open Access Journals

e-revist@s. Plataforma Open Access de Revistas Científicas Electrónicas

Freemasonry and Civil Society Program at UCLA

Fudan University Library Academic Resource Portal

Google académico

Institute for the Study of the Americas at University of London

Latindex (UNAM)

Latindex.ucr. Repositorio de revistas de la Universidad de Costa Rica

Library Catalogue of University of South Australia

Museo Virtual de la Historia de la Masonería de La UNED

Nuevo Mundo. Mundos Nuevos

REDIAL. Red Europea de Información y Documentación sobre America Latina

SciELO - Scientific Electronic Library Online

Sherpa/Romeo

SID. Sistema Integrado de Documentación. Universidad Nacional de Cuyo

Toronto Public Library

UBO. Revues en ligne. Université de Bretagne Occidentale

Universia. Biblioteca de Recursos

University of Saskatchewan Library

University of Wiscosin-Madison Libraries

Western Theological Seminary. Beardslee Library Journals 


\title{
"La historia tiene la palabra. II República española y la masonería 75 años después, en: Cultura Masónica VI, no. 19 (2014), coordinado por Yván Pozuelo Andrés"
}

\author{
José-Leonardo Ruiz Sánchez \\ Profesor Catedrático de Historia Contemporánea de la Universidad de Sevilla, España. \\ Correo electrónico: leonardo@us.es \\ Sitio Web: http://personal.us.es/leonardo/
}

Con ocasión de las bodas de brillantes de la proclamación de la Segunda República española comenzaron a publicarse muchas obras sobre aquel primer y frustrado ensayo democrático del siglo XX. Que el asunto no ha perdido aún fuelle y que todavía es posible encontrar aspectos novedosos en los que sondear cuando se cierra definitivamente esa efeméride al cumplirse de nuevo el 75 aniversario, ahora de su derrumbe (1939), lo viene a demostrar el monográfico que, coordinado por el acreditado masonólogo Yván Pozuelo Andrés, ha dedicado Cultura Masónica a aquel momento en lo concerniente-como no podía ser de otro modo habida cuenta del perfil de la revista- a la relevancia que tuvo la Masonería en aquella coyuntura histórica. Un total de once trabajos, además de la editorial en la que se sitúa el tema realizada por Ignacio Méndez-Trelles Díaz, realizados por nueve destacados investigadores españoles e hispanoamericanos de distinto perfil formativo (mayoritariamente historiadores pero también los hay periodistas, abogados y politólogos; algunos de ellos masones con lo que pueden aportar en su análisis sus propias experiencias) que se reúnen en la obra dando coherencia a una investigación desde distintos puntos de vista.

Ha correspondido al conocido periodista Valentín Díaz una breve reflexión sobre la trayectoria histórica de la Masonería en España, desde su instalación a comienzos del siglo XVIII hasta el momento presente, cuando ha renacido -en expresión suya- de las cenizas a las que la redujo el Franquismo, pasando por la que considera etapa más floreciente, la transcurrida entre el Sexenio y la Segunda República, tras la cual vino el momento de su mayor persecución durante la Dictadura. De una manera expresa se detiene en esta etapa postrera, la actual, en la que analiza las dificultades que padece la Orden desde su legalización en noviembre de 1979: no hay persecución como antes pero es -siempre en su opinión- una institución estancada organizativamente y socialmente irrelevante. La escasa tradición liberal española; la dificultad de administrar la herencia del GOE recién legalizado (en el exilio mexicano desde 1943) lo que dio lugar a que los legítimos representantes del exilio tuviesen que inscribirse legalmente con otro nombre y que las antiguas siglas quedase en manos de la GLE; la proliferación de potencias masónicas y las enemistades intestinas y otros, propician una escasa presencia en sus talleres y la falta de personalidades de relieve lo que paradójicamente no ha impedido el extraordinario conocimiento de la historia de la institución, hecho con rigor, con los estudios impulsados desde el CEHME.

Por su parte Juan Ignacio Cruz Orozco, de la Universidad de Valencia, centra su análisis en el debate sobre la cuestión religiosa, uno de los aspectos angulares de aquellas Cortes democráticas y cuya deriva laicista radical pudo lastrar a juicio de no pocos 
historiadores la dinámica republicana posterior. Centrado en el debate sobre el artículo 26 de la Constitución de 1931 (que concluyó con la disolución de la Compañía de Jesús, fin del auxilio económico a la Iglesia y, entre otros aspectos, la prohibición de toda actividad que no fuese esencialmente eclesial) ni existió en el Gobierno una postura común desde el primer momento en torno a cómo abordar la cuestión religiosa (dividido entre los más radicales y los partidarios de atemperar las propuestas) ni tampoco en los debates parlamentarios, donde buena parte de los masones se abstuvieron si no fueron los principales activistas de posturas conciliatorias. Y en cuanto a la Ley de Congregaciones Religiosas de 1933, que desarrollaba el precepto constitucional, la principal Obediencia española del momento tuvo especial interés en no involucrarse en acciones políticas concretas.

El abogado Ricardo Fernández Rodríguez nos presenta un caso singular, el de la logia Spartacus que en Bayona inició su breve actividad en enero de 1934, a caballo entre dos repúblicas (la Segunda española y la Tercera francesa) y en un contexto de espiral totalitaria en Europa que amenazaba ambas repúblicas. Fue fruto del entendimiento de hermanos pertenecientes a tres logias de ambos lados de la frontera, pertenecientes a Obediencias distintas, con taller que terminó ubicado en Hendaya con patente del Gran Oriente de Francia y del Gran Oriente Español. Política pero no partidista fue un ensayo breve pues sucumbió antes del inicio de nuestra última Guerra Civil.

Por su parte Juan José Morales, de la UNED en Zaragoza y del CEHME, ha centrado su trabajo en una temática sobradamente conocida por él como es la represión de los masones en este caso durante la Guerra Civil española. Tras desgranar las razones de la prioridad en la persecución de los masones desde el bando sublevado (en donde constata la impronta condenatoria católica de antaño) se centra en el proceso, llevado a cabo fundamentalmente por las milicias falangistas y tradicionalistas (requetés) y otros sectores de extrema derecha, para concluir en el castigo que les esperaba a quienes habían estado trabajando entre columnas, una represión que tuvo dos momentos: la llevada a cabo durante la Guerra de una manera desorganizada, casi improvisada y espontánea (sin instrucción sumarial en numerosos casos) y, una vez alcanzada la victoria de Franco, a partir de 1939, de una manera sistemática con primacía de la jurisdicción militar con la puesta en marcha ad doc de una legislación y una maquinaria represiva muy eficiente cuyos últimos coletazos todavía estaban vigentes en los años sesenta. Muy clarificatorio su trabajo en el que nos presenta además todo el marco jurídico en el que se basó la represión y las últimas medidas gubernamentales de reparación llevadas a cabo en momentos recientes.

La investigadora Sylvia Hottinger-Craig, siguiendo los trabajos de María José de la Calzada y de Natividad Albear aborda la vida de dos mujeres masonas unidas por su amistad con Clara Campoamor y por su condición de luchadoras por los derechos de la mujer. Por un lado, Consuelo Álvarez Pool (1867-1957), auxiliar telegrafista iniciada en 1910 en la logia de adopción Ibérica, una de las primeras mujeres de la Asociación de la Prensa de Madrid, de grupo Mujeres Progresista y del Grupo Femenino del Ateneo de Madrid en 1925, que abogó por la educación, los derechos de la mujer y su emancipación en importantes medios de comunicación del país en los años veinte y treinta. De otro, Consuelo Berges (1899-1988), de la logia de adopción Amor, compañera y amiga de Colombine, nacida en el seno de una 
familia librepensadora y republicana cántabra. Tras estudiar magisterio emigró a Perú, más tarde a Argentina (donde polemizó con Maeztu) para regresar a España tras una breve estancia en París al proclamarse la República, encontrando trabajo como bibliotecaria en el Archivo de la Junta Provincial de Beneficencia, lo que le permitió colaborar con distintas publicaciones de izquierda desde las que defendió el voto de la mujer. Al fin de la Guerra marchó a Francia y tras no pocas peripecias que le permitieron vivir clandestinamente en París durante cuatro años fue entregada en España donde se le aplicó la política represiva por su condición de masona. Sus trabajos literarios le llevaron a crear el Stendhal otorgado anualmente a la mejor traducción del francés al español.

El Catedrático mexicano y miembro del CEHME Carlos Francisco Martínez Moreno nos adentra en el conocimiento del papel que jugó la Gran Logia Valle de México, con fuertes vínculos con la masonería española en particular con la GLE, siendo su Gran Maestre quien pidió al presidente Lázaro Cárdenas, también masón, que interviniese en favor de los masones españoles en Francia e hizo llegar al Roosevelt la solicitud del GOE para que enviase a Francia barcos en favor de los refugiados españoles. En realidad, su estudio va mucho más allá porque la situación republicana española cuestionaba los fundamentos de la masonería universal pero también de la Doctrina Estrada establecida por las autoridades mexicanas por la que, el Gobierno, debía mantenerse al margen de emitir juicios acerca de la realidad política interna de otros países y eso a pesar de que sintonizaban con las realizaciones del primer bienio republicano español. Valle de México cuestionó de manera beligerante esta actitud por entender que primaba la ayuda humanitaria a los masones españoles afectados por la guerra, lo que finalmente se tradujo en el Comité Nacional de Ayuda a los Refugiados Españoles. Más allá de lo anterior, lo que nos descubre Martínez Moreno es el seguimiento puntual que estaba recibiendo la masonería mexicana de cuanto acontecía en el país desde la proclamación republicana hasta la política represiva de los sublevados.

El cómo fue recogida en la prensa masónica de La Habana, en particular Mundo Masónico, la Guerra Civil española es analizado por los profesores de la Casa de Altos Estudios Don Fernando Ortiz de la Facultad de Filosofía e Historia Janet Iglesias Cruz y Javiher Gutiérrez Forte. El trabajo recoge la evolución del modelo político cubano en los años treinta con la irrupción de planteamientos ideológicos europeos, incluidos los distintos totalitarismos, la situación de la masonería y los errores cometidos por su relación con la autoritaria clase dirigente cubana, la trascendencia que tuvo la nutrida presencia de españoles en la Isla, los cubanos que participaron en el conflicto en apoyo de la república, y la relación de sus autoridades con la cambiante realidad peninsular hasta el reconocimiento de Franco en mayo de 1939. En todo ese contexto, Mundo Masónico no dudó en tomar partido por los que luchaban por la libertad, la fraternidad y la dignidad del ser humano.

Hemos dejado para el final los trabajos del coordinador del monográfico, Yván Pozuelo Andrés, sobre quien ha recaído el mayor peso investigador, con tres importantes aportaciones. Brevemente para no hacer más larga esta presentación (y de paso para sugestionar así al lector de su lectura) referimos que en un primer trabajo sitúa el tema y el período analizado, alude a que es el período más estudiado científica y -tambiénplanfetariamente. A pesar de las proclamas de masones y antimasones, los hermanos 
estuvieron ajenos a la construcción y a los grandes acontecimientos de la Segunda República y eso, a pesar de que numerosos masones ocuparon altos cargos, pero también, estuvieron divididos y se terminaron por situar en ambos bandos contendientes y ninguno de ellos. En una segunda investigación, centrado en los sucesos de 1934 en Asturias, analiza el complot judeo-masónico en el Consejo de Guerra al masón, socialista y luego radical-socialista Leoncio Villanueva, que concentró en su persona todas las fantasías inimaginables de los sectores ideológicos más intransigentes del país, siendo condenado a cadena perpetúa. Se le juzgó como director del comité revolucionario y responsable por tanto de todos los desmanes cometidos, entre ellos el asesinato de doce Hermanos de la Doctrina Cristiana, un Padre Pasionista y otros, cuando los masones todos votaron en contra de esa medida. Por último, Pozuelo Andrés nos presenta una exhaustiva selección de 250 referencias bibliográficas sobre la Historia de la Masonería durante la Segunda República. Como decimos, sin duda, es la aportación más extraordinaria para el monográfico que incluye finalmente un apartado con las fechas y datos generales sobre la masonería española entre 1931 y 1939. 